\title{
Medicine: Prevalence and Types of Injuries among Patients treated in Teaching Hospital, Batticaloa
}

\author{
Article by MI Haseemdeen \\ Faculty of Health-Care Sciences Eastern University, Sri Lanka \\ Email:-mi.hazeem@gmail.com
}

\begin{abstract}
Background: Injuries are the leading causes of death, hospitalizations and disabilities. Traumatic injuries, poisoning and burns are the major types of injuries reported in Sri Lanka, according to the National Health Statistics. Life style changes such as using alcohol and increasing of vehicle usages are believed to be having relation with the prevalence of injuries. Gender and age group also have effects on types of injuries.

Objective: To identify the prevalence of various types of acute injuries in Batticaloa, Teaching Hospital.

Method: It is a cross sectional descriptive study involving simple random sample of one hundred and ninety one (206) injured patients who were atmitted at Teaching Hospital, Batticaloa.Data was collected by using a pre designed structured interviewer administered questionnaire.

Results: Altogether, 206 patients with an age range of 01-80 years were studied. Males accounted for $62.8 \%$ of the study sample. Majority of causes are dog bite (33.5 $\%)$, and RTA (24.2\%), fall injury (16\%), poisoning (6.3\%) and Cat bite (8.7 $\%)$.Among that, $50 \%$ injuries are occur due to the animals in whole injuries. There was a significant relationship between age groups and causes of injuries and there was no relationship between habit of alcohol use and accidental injuries. Among body parts, upper limb (35\%) and lower limb (53\%) are most often affected by injuries. 11. $165 \%$ of injured people get disabilities due to their injuries.

Conclusion: According to this study, majority of injuries are caused by dog bites, road traffic accidents (RTA), fall injuries, poisoning and cat bites respectively. Considering the affected body parts, injuries in upper extremities and lower extremities are more common. Around 11. $2 \%$ of patients get disabilities as the consequences of their injuries.
\end{abstract}

Keywords: Prevalence, Dislocation, Laceration, Upper limb, Lower limb, Skull, Amputation, Linear, Exponential, Strain, Domestic, Stray, Fatal injuries.

Abbreviation: n-number of patients, RTA- Road Traffic Accidents.

\section{Introduction}

\section{Background}

Injuries are the leading causes of death, hospitalizations and disabilities throughout the world accounting for $9 \%$ of all deaths and $16 \%$ of the burden of disability annually (1). Injuries account for approximately $11 \%$ of all hospital admissions in Sri Lanka (2).

They are also a major public health problem in the South East Asia Region (SEAR) including Sri Lanka. Injuries ranked $5^{\text {th }}$ among all causes of death in the region and was more prominent in the 15-44 years age group (3).

\section{Current situation in sri lanka}

Traumatic injuries, poisoning and burns are the major types of injuries reported in the National Health Statistics. Traumatic injuries continue to be the leading cause of 
South American Journal of Medicine

Special Edition 2016

hospitalization since 1995. In 2007, there were 669,052 admissions (proportionate morbidity $16.1 \%$ ) and 1389 deaths (proportionate mortality $4.0 \%$ ) in the government hospitals due to traumatic injuries. In the same year, there were 62,721 admissions due to poisoning. This includes 17,723 (28.3\%) due to pesticides and 44,998 (71.7\%) due to substances such as drugs, medicaments and biological substances and nonmedicinal substances. Poisoning leads to $4.5 \%$ (1561) of deaths reported in the government hospitals. Furthermore, there was a total of 13,409 hospital admissions and 292 deaths due to burns and corrosions (4). In 2005, injuries (both intentional and unintentional) accounted for $19.1 \%$ of all registered deaths in Sri Lanka (3).

The purpose of this study is to assess the prevalence level of acute injuries and to design the guidelines to reduce the high incidence rate of injury.

\section{Objectives}

General objective: To identify the prevalence of various types of acute injuries in Batticaloa, Teaching Hospital.

\section{Specific objectives}

a. To identify the causes of injuries.

b. To classify the types of injuries and affected body parts associated with injuries.

c. To describe the disability.

\section{Literature review}

A study was carried out on Population-based estimates of injuries in Sri Lanka. In this study individuals of all ages were selected from 2000 households in a populationbased cross-sectional survey using a stratified cluster sampling technique. The results describe that most of injuries are mechanical injuries, followed by road traffic injuries. The annual injury mortality rate and disability rate were 177 and 290 per 100000 population, respectively (5).

A study was conducted on Incidence of Physical Injuries in a Rural Community in Sri Lanka. A rural community consisting of 225 families with 1029 inhabitants was studied. Data on major injuries for a period of one year were collected retrospectively. Animal bites being the most common cause of injury was noted in $2.3 \%$ of the population followed by falls in $1.6 \%$, contact with objects in $1.5 \%$, cut injuries in $1 \%$ and road trauma in $1 \%(2)$.

The data were obtained on estimating the incidence of road traffic fatalities and injuries in Sri Lanka using multiple data sources. They used data from multiple sources to estimate the incidence of fatal and non-fatal road traffic injuries in Sri Lanka. They validated the accuracy of the data from the national traffic police by comparing with estimates based on national death registration. For estimating the incidence and patterns of non-fatal injuries, used a nationally represented health survey (6), and data on hospital admissions from a rural setting (Galle district). Estimate that in the year 2005, approximately 2300 people died in Sri Lanka due to road traffic crashes, approximately 300,000 were injured in non-fatal crashes and approximately 140,000 received care for their injuries at hospitals. While the road traffic death rate in Sri Lanka is low compared with other low-income countries, it has been steadily rising for several years. Although young adults are at high risk in nonfatal crashes, the elderly have the highest death rate (7).

A Descriptive cross-sectional study was carried out on incidence and predictors of onboard injuries among Sri Lankan flight attendants. All flight attendants undergoing their annual health and first aid training were invited to participate. Flight attendants who flew continuously for a six-month period prior to data collection were included in the study sample. Recall history of injuries for a period of six months was recorded. 
The study sample consisted of 98 (30.4\%) male and 224 (69.6\%) female flight attendants. The leading causes of injury was pulling, pushing or lifting $(60.2 \%)$. The commonest type of injuries were strains and sprains $(52.3 \%)$. Turbulence related injuries were reported by 38 (29.7\%) flight attendants. The upper limbs $(44.5 \%)$ and the back $(32 \%)$ were the commonest sites affected. After controlling for other factors, female flight attendants had 2.9 times higher risk of sustaining and injury than males (8).

A research work was conducted on injury patterns in rural and urban Uganda Community health workers interviewed adult respondents in households selected by multistage sampling, using a standardized questionnaire. In the rural setting, 1673 households, with 7427 persons, were surveyed. The study reveal that, total incidence of fatal, disabling, and recovered injuries was 116/1000/year. Leading causes of death were drowning in the rural setting, and road traffic in the city (9).

The data was estimated from a research study on injury, incidence and injury patterns in professional football in Sweden. The first team squads of 23 teams selected by the Union of European Football Associations as belonging to the 50 best European teams. The injury incidence during matches was higher than in training. The single most common injury subtype was thigh strain, representing $17 \%$ of all injuries. Reinjuries constituted $12 \%$ of all injuries, and they caused longer absences than non-reinjuries. The incidence of match injuries showed an increasing injury tendency over time in both the first and second halves. Traumatic injuries and hamstring strains were more frequent during the competitive season, while overuse injuries were common during the preseason. Training and match injury incidences were stable over the period with no significant differences between seasons (10).

A Cross-Sectional study was carried out on incidence and nature of all injuries sustained by elite Western Australian junior Rugby Union players during the 26 weeks up to and including the 1997 National Championship campaign. Injury data were analyzed by phase of play, position, severity and if occurred at games or training. The incidence of injury was significantly associated with the position played and the phase of play in which the injury occurred. Tackling was the most dangerous phase of play (52\% of injuries) and the most common site of injury was the lower limb (37\%). Most injuries occurred during games (56\%) and the flanker was the position most at risk of injury (12\%) (11).

A research work was conducted on population based estimates of non-fatal injuries in the capital of Iran. The estimated household was selected for this study. 2,450 households residing in Tehran during 2007-8. The annual incidence of all injuries was 188.7 , significant injuries needing any medical care was 68.8 , fractures was 19.3 , and injuries resulted in hospitalization was 16.7 per 1000 population (12).

\section{Methodology}

\section{Study design}

Cross sectional descriptive study.

\section{Study area}

Medical, Surgical, Orthopedic wards, and Emergency Treatment Unit (ETU) at Teaching Hospital, Batticaloa

\section{Study population}

The patient who are admitted with acute injuries in the above wards and special unit atTeachingHospital, Batticaloa 
South American Journal of Medicine

Special Edition 2016

Sampling method, research method\& sample size

Simple Random sampling method was used to obtain the 206 samples for our study.

Inclusion criteria Patients who admitted with acute injuries at the Teaching Hospital, Batticaloa will be included.

Exclusion criteria The patients who are unable to speak due to altered conscious level, oral injuries or other reasons will be excluded from this study.

\section{Study period}

June 2013 to November 2013.

\section{Study instrument}

Data was collected by using a pre designed structured interviewer administered questionnaire.

\section{Data collection}

Self-introduction was done and the purpose of this study was explained to the subjects. Each patient wasstudied individually to avoid the influence by the others and the interviewer administrated questionnairewas filled by the investigator. All the details in the interviewer administrated questionnaire were collected on the basis of their oral statement at the particular time. Researchers did not interfere with their answers. The same procedure was done during our entire study period.

\section{Data analysis}

Questionnairewascoded and statistical analysiswas done using SPSS (version 16) analytical package.

\section{Ethical consideration}

The proposal was submitted to the Ethical Review Committee, Faculty of Health Care Sciences to obtain the ethical clearance. Permission was obtained from Director, Teaching Hospital, and Batticaloa. After explaining the purpose of the study, informed consent was obtained from each participant before data collection. The questionnaires was coded and subjects was identified by a number but not by their names. Privacy, confidentiality and anonymity of the subjects was ensured during interviews and afterwards.

\section{Results}

Table1. Description of study sample

\begin{tabular}{llll}
\hline Variables & Response & Number $(\mathrm{n}=206)$ & Percentage $(\%)$ \\
\hline Gender & Male & 131 & 62.8 \\
& Female & 75 & 37.2 \\
Age group & 01-20 years & 30 & 14.6 \\
& 21-40 years & 86 & 41.7 \\
& $41-60$ years & 57 & 27.7 \\
Alcohol use & 61 - 80 years & 33 & 16.0 \\
& Yes & 64 & 31.0 \\
Smoking & No & 142 & 69.0 \\
& Yes & 79 & 38.3 \\
Occupation & No & 127 & 61.7 \\
& Farmer & 8 & 3.9 \\
& Business man & 6 & 2.9 \\
& Officers & 11 & 5.3 \\
\hline
\end{tabular}




\begin{tabular}{lll}
\hline Technician & 6 & 2.9 \\
Fisher man & 11 & 5.3 \\
Driver & 13 & 6.3 \\
Field worker & 14 & 6.8 \\
Cooley & 30 & 14.5 \\
Other job & 2 & 1 \\
No Job & 105 & 51 \\
\hline
\end{tabular}

The Table 1 indicates the demographic data which was gained among the participants at teaching Hospital, Batticaloa. That demographical factor described as below. Among the 206 patients $62.82 \%$ of the patients are male and $37.2 \%$ of the students are female. Age group 21-40 and 41-60 is more prone to effect by injuries than group 01-20 and 61-80.Among the clients, 31. \% of the patients are alcohol user and $39 \%$ are smoker. Nearly half of the patient have no any occupation.

Table 2. Causes of injuries

\begin{tabular}{lll}
\hline Causes & Number & Percentage \% \\
\hline Assault & 5 & 2.4 \\
Snakebite & 6 & 2.9 \\
RTA & 50 & 24.3 \\
Fall Injury & 33 & 16 \\
Dog bite & 69 & 33.5 \\
Cat bite & 18 & 8.7 \\
Cut-Injury & 3 & 1.5 \\
Rate bite & 1 & 0.5 \\
Wasp bite & 1 & 0.5 \\
Stab injury & 2 & 1.0 \\
Burn & 5 & 2.4 \\
Poisoning & 13 & 6.3 \\
\hline Total & 206 & $100 \%$ \\
\hline
\end{tabular}

Table 2 illustrates the classification, the prevalence and the percentages of the various causes for injuries among the patients admitted with the history of injury, at teaching Hospital, Batticaloa. In that results, majority of causes are dog bite (33.5\%), RTA $(24.25 \%)$, fall injury (16\%), Poisoning (6.3\%) and Cat bite $(8.7 \%), 50 \%$ injuries are occur due to the animal in whole injuries.

Table 3. Association between age groups and causes of injuries

\begin{tabular}{|c|c|c|c|c|}
\hline \multirow[t]{2}{*}{ Age Groups } & \multicolumn{3}{|c|}{ Major causes of injury } & \multirow[b]{2}{*}{ P-value } \\
\hline & RTA & Fall Injury & Dog bite & \\
\hline $1-20$ & $8(29.6)$ & $12(44.4)$ & $7(25.9)$ & 0.46 \\
\hline $21-40$ & $22(36.6)$ & $5(8.3)$ & $33(54.7)$ & 0.005 \\
\hline 41-60 & $14(34.1)$ & $7(17.07)$ & $20(48.7)$ & 0.045 \\
\hline $61-80$ & $6(25)$ & $9(37.4)$ & $9(37.4)$ & 0.69 \\
\hline
\end{tabular}

RTA -Road Traffic Accident

The Table 3 results revealed that there was no a significant relationship between the Ages group 1-20, 61-80 and Causes of injuries $(\mathrm{P}>0.05)$ and according the above results, there was a significant relationship between Age group 21-40, 41-60and causes of injuries $(P<0.05)$. So, Age group 21-40 and 41-60 are more prone to effected by RTA and Dog bite than fall injuries.

Table 4. Association between alcohol use and accidental injuries.

\begin{tabular}{llll}
\hline & \multicolumn{4}{l}{ Accidental Injury } \\
\cline { 2 - 4 } Age Groups & RTA & Fall Injury & P-value \\
\hline Yes & $16(66.6)$ & $8(33.3)$ & 0.10 \\
No & $34(57.6)$ & $25(42.3)$ & 0.24 \\
\hline
\end{tabular}


South American Journal of Medicine

Special Edition 2016

Table 4 results indicate that, weather alcohol user or non-user, there was no a significant relationship between patient and accidental injuries $(\mathrm{P}>0.05)$.

Table 5. Types of injuries

\begin{tabular}{lll}
\hline & Number & Percentage \% \\
\hline Type of Injuiry & 2 & 1 \\
Dislocation & 2 & 2 \\
Strain & 38 & 18.5 \\
Fracture & 54 & 26.2 \\
Trauma/Wound & 71 & 34.6 \\
Puncture/Bite injury & 22 & 10.1 \\
Scratching & 3 & 1.5 \\
Abdominal Injury & 8 & 3.9 \\
Head Injury & 3 & 1.5 \\
Laceration & & 100 \\
\hline Total & 206 & \\
\hline
\end{tabular}

Table 5 Describes the prevalence of type of injuries. Nine type of injuries are most frequently occur in Batticaloa. Among that fracture (18.5\%), trauma/wound (26.2\%), puncture/bite injury (34.6\%) and scratching (10.1\%) are major types.

Table6. Affected body parts associated with injuries.

\begin{tabular}{lll}
\hline Affected Body Part & Number & Percentage $\%$ \\
\hline Head & 8 & 3.8 \\
Face & 7 & 3.3 \\
Chest & 4 & 1.9 \\
Upper limb & 72 & 35 \\
Rib & 2 & 1 \\
Abdomen & 3 & 1.4 \\
Lower limb & 110 & 53 \\
\hline & 206 & 100 \\
\hline
\end{tabular}

Table 6 results are accounted the frequencies and percentage of affected body parts. In that, upper limb (35\%) and lower $\operatorname{limb}(53 \%)$ are more prone to affected by the injuries.

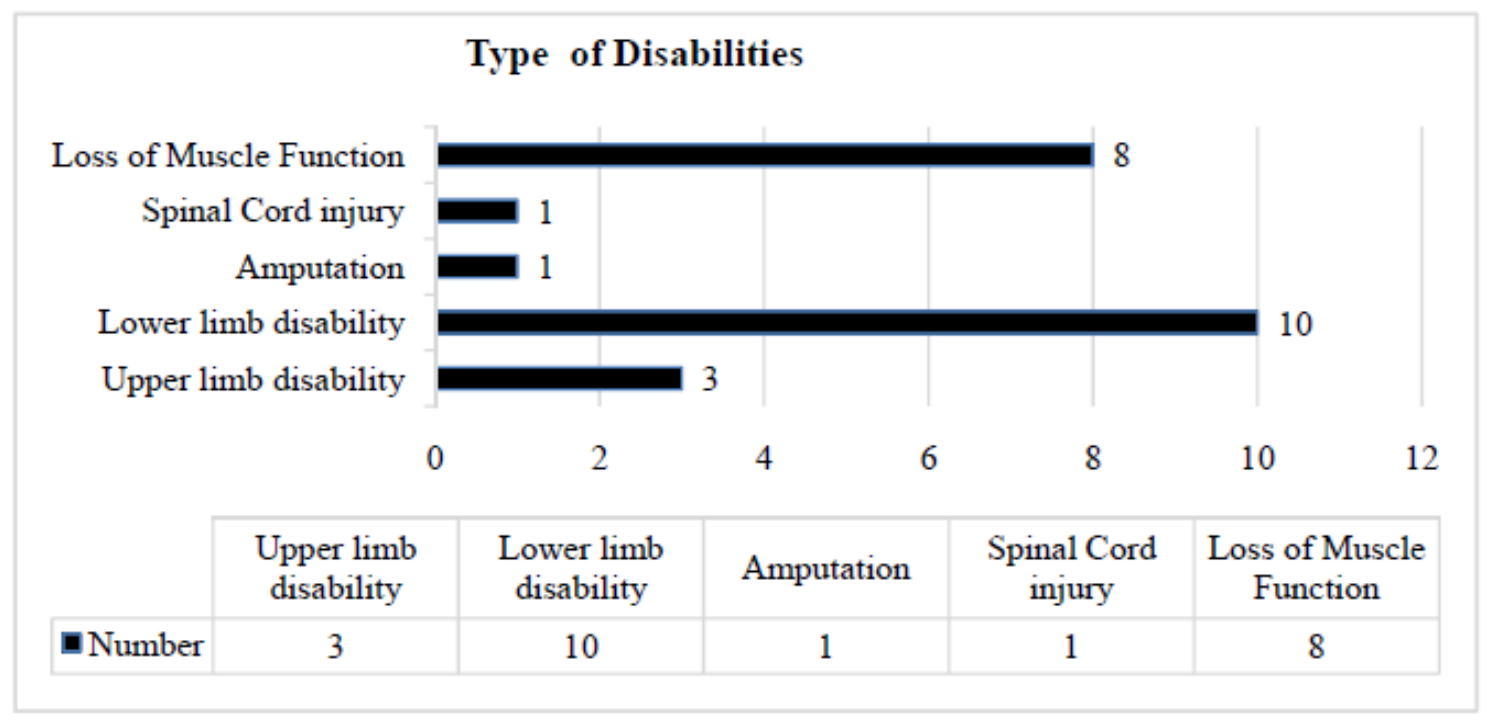

Figure 1. Type of disabilities. 
Figure 1 illustrate that which types of the disabilities are occur due to the injuries. In the disabilities, lower limb disability and loss of muscle function have high prevalence rate. Lower limb disability are most often occurred by the fracture.

\section{Discussion}

Traumatic injuries, poisoning and burns are the major types of injuries reported in the National Health Statistics (3).But, present study in Batticaloa reported that, majority of causes are dog bite (33.5\%), RTA (24.2\%), fall injury (16\%), Poisoning $(6.3 \%)$ and Cat bite $(8.7 \%)$. In Batticaloa $50 \%$ injuries are occur due to the animal in whole injuries.

In the present study, the results revealed that there was no a significant relationship between the Ages group 1-20, 61-80 and Causes of injuries $(\mathrm{P}>0.05)$ and according the results, there was a significant relationship between Age group 21-40, 41-60 and causes of injuries $(\mathrm{P}<0.05)$. So, Age group 21-40 and 41-60 are more prone to effected by RTA and Dog bite than fall injuries. A Study conducted on Epidemiological Study of Road Traffic Accident Cases describe that, the highest number of RTA victims (31\%) were found between the age group of 20 and 29 years (13).Another study on knowledge, attitude and practice following dog bite, reported that, majority of the study subjects were in the age group of 15-44 followed by 5-14.A large percentage of the subjects $(31.1 \%)$ was, in fact, in the age group of 30-44 followed by those in the 15-29 age group (28.8\%) (14).

Another Study carried on falls incidence underestimates the risk of fall-related injuries in older age groups show that, the risk of fall-related injuries, calculated on the basis of the incidence of fall-related injuries, showed a linear relationship with age, whereas the risk calculated on the basis of fall-related injuries corrected for exposure (falls risk by exposure, FARE) showed an exponential relationship. Calculations on the basis of the incidence of fall-related injuries underestimated the risk of fall-related injuries in people aged 70 years and older, and especially in women (15).

Alcohol is one of the most important risk factors for serious and fatal injuries, contributing to approximately one third of all deaths from accidents. One study showed that the speed of the vehicle at the time of collision is high when blood concentration of alcohol is high. One Norwegian study showed that $11.5 \%$ of the drivers of accident were under the influence of alcohol. In another study group $32 \%$ of the victims were with a history of alcohol use (16).In the present study, the results indicate that, weather alcohol user or non-user, there was no a significant relationship between patient and accidental injuries $(\mathrm{P}>0.05)$. So, in the Batticaloa, alcohol use or non-use not associated with accidental injuries.

Most frequently, nine (9) type of injuries are occur in Batticaloa. Among that Fracture (18.5\%), Trauma/Wound (26.29\%), Puncture/Bite injury (34.6\%) and Cat bite $(10.1 \%)$ are major types and considering the affected body parts, injuries in upper limb (35.\%) and lower limb (53\%) are most common. Among that, $11.2 \%$ of patients get disabilities as the consequences of their injuries.

\section{Limitations}

The finding of this study cannot be generalized to all injured patients due to small sample size $(\mathrm{n}=206)$.

ETU, Surgical Wards and ICU were very rush and most of the time, there was no comfortable situation to interview patient. The interviews conducted to administer the questionnaires were done inside a clinic environment while waiting to consult the doctor. There were some disturbances during the interview which was unavoidable. 
South American Journal of Medicine

Special Edition 2016

\section{Conclusion}

A study was conducted on Prevalence and Types of Injuries among Patients treated in Teaching Hospital, Batticaloa. The study results describes majority of causes for injuries in Batticaloa region. The leading causes are dog bite, RTA, fall injury, Poisoning and Cat bite respectively in descending order. Among then injured individuals, $50 \%$ of injuries are due to the animal bites. The people belong to the age groups 21-40 and 41-60 are more prone to be affected by the RTA and Dog bite. When we consider the affected region of the body, upper limb (35\%) and lower limb $(53 \%)$ are most often affected by injuries.

\section{Recommendation}

\section{Recommendation for patients who are involve in dog bite}

a Do not approach an unfamiliar dog.

b Remain motionless when approached by an unfamiliar dog.

c Avoid direct eye contact with a dog.

\section{Recommendation for older to prevent fall injury}

Exercise regularly. It is important that the exercises focus on increasing leg strength and improving balance, and that they get more challenging over time.

\section{Recommendation for road user and driving license provider}

There is clearly a need for road safety education and it should be directed towards road users, who are frequently involved and injured in RTAs

\section{Acknowledgement}

I would like to express my deep gratitude to Rev.Sr.Dr.J.Joseph, Senior Lecturer, Department of Supplementary Health Sciences, Faculty of Health Care Sciences, and Mr.S.Sujendran, Lecturer, Department of Supplementary Health Sciences, Faculty of Health Care Sciences for valuable suggestions and guidance to research study.

I thank the Ethical Clearance Committee, Faculty of Health Care Sciences, and Eastern University, Sri Lanka for approval of my research proposal.

I thank the Director, Teaching Hospital, and Batticaloa for permission to follow my research study in Teaching Hospital, Batticaloa.

I would like to thank staffs of ETU, Surgical wards and ICU, Teaching Hospital, and Batticaloa for encouragement and support in my research study.

\section{References}

[1]. World Health Organization (WHO), NLM classification: WA 530.1, The world health report, 2006.

[2]. Lamawansa MD, Piyathilake A. Incidence of Physical Injuries in a Rural Community in Sri Lanka: Results of the First Community Survey in Sri Lanka. Indian J Community Med2008; 33(4): 238-242.

[3]. Ministry of Health, Sri Lanka, National Policy \& Strategic Framework on Injury Prevention \& Management in Sri Lanka, 2009.

[4]. Ministry of Health, Sri Lanka, Annual Health Bulletin, 2009.

[5]. Navaratne KV, Fonseka P, Rajapakshe L, Somatunga L, Ameratunga S, Ivers R, Dandona R. Population-based estimates of injuries in Sri Lanka, Inj Prev2009; 15:170-175.

[6]. World Health Organization (WHO), World Health Survey, 2002.

[7]. Bhalla K, Navaratne KV, Shahraz S, Bartels D, Abraham J, Dharmaratne S. Estimating the incidence of road traffic fatalities and injuries in Sri Lanka using multiple data sources, International Journal of Injury Control and Safety Promotion2010; 17(4): 239-246.

[8]. Alamode SB, Dharmaratne SD, Alamode TC. Incidence and predictors of onboard injuries among Sri Lankan flight attendants, BMC Public Health2009; 9:227. 


\section{South American Journal of Medicine Special Edition 2016}

[9]. Kobusingye O, Guwatudde D, Lett R. Injury patterns in rural and urban Uganda, Inj Prev 2001; 7:46-50.

[10]. Ekstrand J, Hägglund M, Waldén M. Injury incidence and injury patterns in professional football, Br J Sports Med 2011;45:553-558.

[11]. McManus A, Cross DS. Incidence of injury in elite junior Rugby Union, Journal of Science and Medicine in Sport 2004; 7(4):438-445.

[12]. Saadat S, Mafi M, Alhoseini MS. Population based estimates of non-fatal injuries in the capital of Iran, BMC Public Health 2011; 11:608.

[13]. Nilambar J, Srinivasa DK, Gautam R, Jagdish Epidemiological study of road traffic accident cases, Indian Journal of Community Medicine2004; 29(1):20-20.

[14]. Agarvval N, Reddaiah VP. Knowledge, attitude and practice following dog bite, Health and Population Perspective and Issues 2003; 26 (4):154-161.

[15]. Etman A, Wijlhuizen GJ, Heuvelen MJ, Chorus A, Hopman M. Falls incidence underestimates the risk of fall-related injuries in older age groups, Age and Ageing 2012; 41: 190-195.

[16]. Weerawardena WAK, Illanagasingha TDB1, Piyadasa IJ, Rathnayaka SM, Subaweera WTDUPL, Niroshana GAL. Analysis of patients admitted with history of road traffic accidents to surgical unit B Teaching Hospital Anuradhapura, Sri Lanka, Anuradhapura Medical Journal 2013; 7(1): 2-5. 